Supplementary Information for

\title{
Advancing Laboratory Characterization and Qualification of Additives for Hydrate Slurry Flow in Multiphase Systems
}

\author{
Jeong-Hoon $\mathrm{Sa}^{1,2}$ and Amadeu K. Sum ${ }^{1 *}$
}

${ }^{1}$ Phases to Flow Laboratory, Chemical \& Biological Engineering Department, Colorado School of Mines, Golden, CO 80401 - USA

${ }^{2}$ Department of Chemical Engineering (BK21 FOUR), Dong-A University, Busan 49315 KOREA

*Corresponding author E-mail: asum@mines.edu 


\section{Flash Calculation of the Gas Composition}

For all experiments, a synthetic natural gas mixture was used. While the feed composition is known, the gas phase composition can slightly change during gas solubilization in oil and water phases at constant temperature. In addition, when the cooling is applied to reach a desired temperature for hydrate formation, the gas composition can change as well. It is important to consider the dissolution of the gas and the gas composition when determining the driving force for hydrate formation, as depending on the systems and conditions. The flash calculations were thus performed using PVTsim ${ }^{\circledR}$ Nova (Calsep A/S, Version 4.0) to see if such changes are significant. Figure S1 shows that the gas composition changes only slightly, and therefore the change in the hydrate equilibrium boundary is relatively small. Under $30 \%$ liquid loading, $25 \%$ water cut, and with $3 \mathrm{wt} \%$ $\mathrm{NaCl}$ added, the subcooling temperature only changes by $0.4{ }^{\circ} \mathrm{C}$. Such small changes can thus be neglected in calculations of the driving force and water conversion.
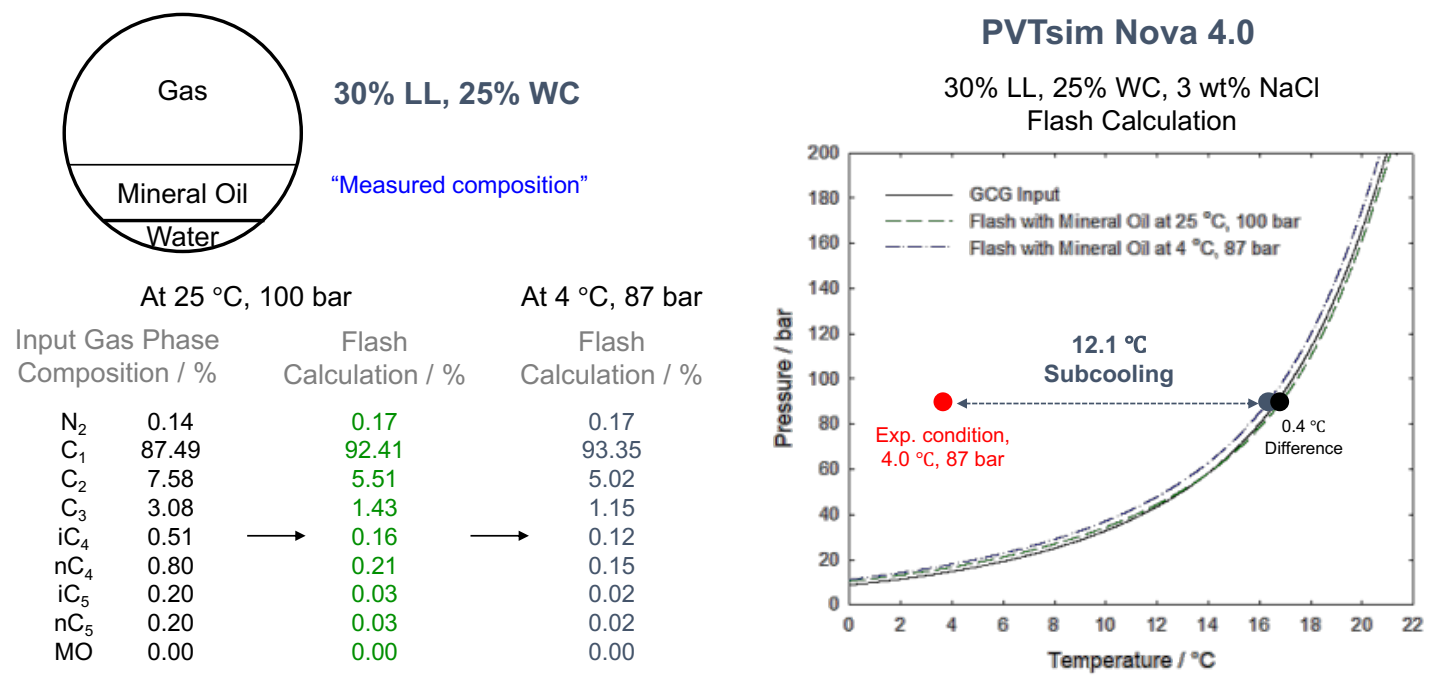

Figure S1. An example flash calculation of the gas phase compositions.

\section{Videos from Tests in the Rock-Flow Cell}

Videos for each of the time segments shown in Figures 5, 7, and 10 in the main text are available to provide further details on the process of hydrate formation, agglomeration, deposition, and bedding. The videos are labeled by figure number, test number, test mode, and time segment. the videos are in MP4 format. 